\title{
ANTHROPOGENICALLY INDUCED ECOSYSTEM DYSFUNCTION AND HUMAN HEALTH
}

\section{Asonye Christian Chinedu, Leslie Tabitha Amere, Sodimu Jeminat, Fadipe Ololade and Kenai Nanchak Dandam}

Babcock University School of Nursing, Ilisan Remo, Ogun State, Nigeria.

Email: christianasonye1@gmail.com

Cite this article:

Asonye C.C., Leslie T.A., Sodimu J., Fadipe O., Kenai N.D. (2021),

Anthropogenically Induced Ecosystem Dysfunction and Human Health. African Journal of Environment and Natural Science Research 4(3), 48-58. DOI: 10.52589/AJENSRWOLHRYON.

\section{Manuscript History}

Received: 8 June 2021

Accepted: 5 July 2021

Published: 24 July 2021

Copyright $\odot 2020$ The Author(s). This is an Open Access article distributed under the terms of Creative Commons AttributionNonCommercial-NoDerivatives 4.0 International (CC BY-NC-ND 4.0 ), which permits anyone to share, use, reproduce and redistribute in any medium, provided the original author and source are credited.

\begin{abstract}
Health is the most basic human right and one of the most important indicators of sustainable development. Individuals, communities and societies depend on healthy ecosystems support to remain healthy. Well-functioning ecosystems provide goods and services essential for human health. These goods and services include nutrition and food security, clean air and fresh water, medicines, cultural and spiritual values, and contributions to local livelihoods and economic development. They can also help to limit disease and stabilize the climate. However, over the years human activities have been constantly placing pressure on earth's natural resources to meet the demands of the economies and the needs of a rapidly growing global population, which has resulted in the transformation of basic natural processes such as weather/climate, biogeochemical cycling, and more so the biological diversity in which the evolutionary changes depend. It is projected that less than $25 \%$ of Earth's surface remains free from substantial impacts of human activities and the proportion is set to fall to a mere $10 \%$ or less by 2050. Constant human activities are resulting in soil, water and air pollution, increased emissions of greenhouse gases, deforestation and land use change, expanded urban areas, introduction of non-native species, and inadequately planned development of water and land resources to meet food and energy needs. These changes are having both direct and indirect impacts on our climate, ecosystems and biological diversity and human health. Thus, the integrated course of action that involves both individual and the government efforts must be instituted to tackle both human-induced drivers of biodiversity loss, disease emergence and the loss of ecosystem services that support health and general human well-being.
\end{abstract}

KEYWORDS: Anthropogenic, Ecosystem, Biodiversity, Health, Dysfunction, Ecosystem Services 


\section{INTRODUCTION}

The term ecosystem (biome) refers to a geographical area where every living (biotic) organisms and non-living (abiotic) interact together to form a bubble of life. These organisms tend to establish complex relationships and continually interact with their physical environment for survival. There are two primary types of an ecosystem in which all other types may fall into: terrestrial or aquatic. The terrestrial ecosystem encompasses all landrelated ecosystems such as forests, grassland, deserts, and tundra ecosystems. On the other hand, aquatic ecosystem encompasses all water-related ecosystems such as freshwater and marine ecosystems. The ecosystems have been supplying range services of great importance to human well-being, health, livelihood and survival (TEEB Synthesis, 2010).

\section{Ecosystem Services}

According to the Millennium Ecosystem Assessment (MEA 2005), ecosystem services are referred to as 'the benefits people obtain from ecosystems', both natural and managed. There are four significant classifications of ecosystem services: provisioning, regulating, cultural and supporting services. Provisioning Services include benefits people can get from nature such as Fruits, vegetables, trees, fish, and livestock. It also includes drinking water, timber, wood fuel, natural gas and oils, plants processed into clothes and other materials, and medicinal benefits. Regulating Services are benefits provided by ecosystem processes that moderate natural phenomena such as pollination, decomposition, water purification, erosion and flood control, carbon storage, and climate regulation.

Cultural Services are intangible / non-material benefits that contribute to the development and cultural advancement of people. It includes how ecosystems play a role in local, national, and global cultures, building knowledge and spreading ideas, creativity born from interactions with nature (music, art, architecture) and recreation. Supporting services are essential for producing all other ecosystem services such as photosynthesis, nutrient cycling, soil formation, and the water cycle. Moreover, without supporting services, provisional, regulating, and cultural services would not exist (MEA, 2003; 2005).

However, these ecosystems services have been on a decline as a result of human activities that tend to alter its balance. However, some of these threats might not be worrying, as they may be naturally resolved provided that the natural conditions are restored. Nevertheless, others have the potential of destroying the ecosystems and render some or if not all of its life forms extinct. It is unfortunate to note that the danger to ecosystem health and human health posed by anthropogenic activities is real. Daily humans are consistently altering the earth's environment via a variety of ways (e.g., industry, agriculture, recreation, and international commerce), which has resulted in the transformation of basic natural processes such as weather/climate, biogeochemical cycling, and more so the biological diversity in which the evolutionary changes depend. It is projected that less than $25 \%$ of Earth's surface remains free from substantial impacts of human activities and the proportion is set to fall to a mere $10 \%$ or less by 2050 (Intergovernmental Science-Policy Platform on Biodiversity \& Ecosystem Services (IPBES) (Toledo, 2018).

Furthermore, without essential ecosystem services such as clean air, clean water, food, and a hospitable climate, humans and other lives cannot exist. Studies have revealed some of the human and ecological costs of environmental degradation. The continuous increase in the 
human population, coupled with increased human consumption, has aggravated and magnified a significant impact on aquatic and terrestrial ecosystems due to agriculture and urbanization, exploitation of natural resources, transportation, and wastes from domestic, municipal, and industries. There has been an increase in evidence about synthetic chemicals and its effects animal hormone and human endocrine/immune systems that are needed for normal growth, development and disease resistance (Kahn, Philippat, Nakayama, Slama, \& Trasande, 2020). Anthropogenic disturbance of ecosystem nutrient may also diminish plants' capacity to sense, respond to, and or survive an array of environmental stresses and adversely affect the nutrient socks and nutrient dynamics (Gautam, \& Mandal, 2018).

\section{Linkages Between Ecosystem Dysfunction and Human Health}

The causal links between ecosystem dysfunction and human health are complex because they are direct or indirect, and dependent on some modifying factors. Human health depends mostly on ecosystem products and services (such as availability of freshwater, food and energy sources, regulation of floods, soil erosion and disease outbreaks,) necessary for optimal human health and productivity. Ecosystem services also include non-material benefits such as cultural services (educational, aesthetics, and cultural heritage values), recreation and tourism, and spiritual benefits in natural areas. Nevertheless, when human interventions threaten the ecosystem's capacity to provide their goods (e.g. freshwater, food, pharmaceutical products) and their services (e.g. purification of air, water, soil, sequestration of pollutants) significant direct human health impacts may result. Furthermore, the resultant effects on health are determined by the degree to which local population are dependent on the ecosystem services and factors such as poverty which in turn affect vulnerability to changes in factors like access to food and water (WHO, 2020).

\section{Ecosystems and Air Quality}

Worldwide, the rising air pollution levels constitute an overwhelming threat to the ecosystem and human health in recent times. Globally, it is estimated that about 4.2 million people died prematurely in 2016 from bad outdoor air, due to exposure to small particulate matter of 2.5 microns or less in diameter (PM2.5), which result in diseases of the cardiovascular and respiratory systems, and cancers. Moreover, about 58\% of the outdoor air pollution-related premature deaths resulted from ischaemic heart disease and strokes, while $18 \%$ of deaths were caused by chronic obstructive pulmonary disease (COPD) and acute lower respiratory infections, and $6 \%$ of deaths were due to lung cancer. Also, about 91 per cent of these deaths occur in low- and middle-income countries (World Health Organization, 2018). Airborne pollutants have the potential of travelling a long distance, linking ecosystems from various regions of the world.

Some ecosystems can suffer elevated health burdens due to the fluctuation of air currents and or topography and thus act as sinks for the residues of atmospheric contamination. Air pollution may affect the forest trees at the cellular, plant, species and ecosystem levels. Air pollution impacts can be direct, such as ozone injury to leaf physiology and tree health. The impacts can also involve some kind of chemical transformations in the environment that can lead to broader ecosystem disruption. For instance, air pollutants such as sulfur dioxides and nitrogen oxides from fossil fuels/coal-burning power plants, factories, and automobiles can react with atmospheric moisture (water), oxygen, and other substances to make up sulfuric and nitric acids, which fall to the earth as acid rain. 
The acid rain can change the soil's composition, reduces the $\mathrm{pH}$ levels of lakes and other surface waters, and raises the solubility of metals such as aluminium and mercury that usually have low biochemical availability. These effects tend to reduce the number of plant and animal species, and especially the aqueous ecosystems can support, thereby disrupting the energy and nutrient relations of the surrounding environments. Also, pollutant-induced depletion of our planet protective ozone layer tend to allow more UV radiation to reach the earth's surface, and this has the potential of igniting cascades of biochemical reactions in the DNA with a resultant increase in the rate of genetic mutation and increase in the risks of skin cancer among humans. In these and several other ways, human disruption of one resource can "spillover" and influence other critical life-support systems.

\section{Ecosystems and Water Quality}

Water is essential for animal and human survival. It is vital to many sectors of the human economy, and they are under pressure due to human activity. The world's water exists naturally in different forms and locations: in the air, on the surface, below the ground and in the oceans. Just $2.5 \%$ of the earth's water is freshwater, and most are frozen in glaciers and ice sheets. About $96 \%$ of all liquid freshwater can be found underground. The remaining small fraction is on the surface or in the air.

Human activities resulting in sedimentation, pollution, climate change, deforestation, landscape changes, and urban growth is a serious threat to water resources around the globe. In developed world, significant urbanization is associated with industrialization which tends to increase the succession of water quality problems related to pathogens, eutrophication, heavy metals, acidification, organic compounds, and sediments from municipal, industrial and agricultural waste sources (Revenga \& Mock, 2000). For instance, in rapidly developing countries such as Brazil, China and India, similar water problems have emerged over the last few decades. However, in other developing countries, water pollution is still a problem and is one of the single most common causes of poor livelihood and bad health (Lenton, 2004).

One of the most severe threats to water resources is the degradation of ecosystems, which often occurs through changes to landscapes such as the clearance of forests, the conversion of natural landscapes to farmland, urbanization, the construction of roads, and surface mining. Sediments occur in water bodies naturally, and it may also occur through several human activities. When sediments occur excessively, they can dramatically change water resources. Sediments occur in water mainly due to mam-made acts such as land-use changes, and agricultural practices and activities such as farming, clearing of forests, the building of roads, and mining which tend to put too much soil and particulate matter in rivers. However, sediment loads can occur naturally in poorly vegetated terrains and most commonly in arid and semi-arid climates following high-intensity rainfall.

Unfortunately, recently an increasing source of high sediment loads is attributed to the building of novel roadway in developing nations where little or no attention is given to the impacts of such human activities on the aquatic systems and the downstream water supplies. Globally, the effects of excessive sedimentation not only affect freshwater systems, but it also threatens the coastal habitats, wetlands, fish and coral reefs in marine environments. The plants and animals are harmed by toxic chemicals from the sediments carried into the water, through smothering fish eggs and small organisms used by fish as food, raising the water temperature, and reducing the amount of sunlight penetrating the water. The resultant effect 
is a reduction in aquatic life, especially fishes which humans depend on for food. And lack of protein in diets could result in protein deficiency, and severe protein deficiency is called kwashiorkor.

Furthermore, humans have long been using air, land and water resources as 'sinks' to dispose of the wastes generated, thereby leaving most wastes inadequately treated, and causing environmental pollution. For instance, the atmospheric contamination from industrial power plants and motor emissions results in a dry and wet deposition, which causes acidification of surface water and groundwater sources, and also, leads to the destruction of the ecosystems. Acid deposition compromises the water quality of lakes and streams via lowering $\mathrm{pH}$ levels (i.e. increasing acidity), and increasing aluminium concentrations. The high concentrations of aluminium and increased acidity reduce species diversity and the abundance of aquatic life in many lakes and streams.

While fish have received the most attention to date, entire food webs are often negatively affected. The potential public health impact of environmental contaminants emanating from industrial, agricultural, medical and everyday household practices, i.e., cosmetics, detergents and toiletries should be a subject for concern. A variety of pharmaceuticals including painkillers, tranquillizers, anti-depressants, antibiotics, birth control pills, estrogen replacement therapies, chemotherapy agents, anti-seizure medications, are finding their way into our environment, via human and animal excreta from disposal into the sewage system and from landfill leachate which may impact groundwater supplies. Agricultural practices are a significant source, and about 40 per cent of antibiotics produced are offered to livestock as growth enhancers. The manure, containing traces of pharmaceuticals, is often spread by farmers on their land as fertilizer from which it can leach into local streams and rivers resulting in the transmission of diseases like cholera, diarrhoea, dysentery, hepatitis A, typhoid, and polio.

Human use of fertilizers is also a contributor to the devastation of the ecosystem health and human health. In the bid to make crops grow faster and make more money, humans use nitrogenous fertilizers. However, the excessive usage of these fertilizers in agriculture has had devastating effects on human health and the environment, as it has contributed to the pollution of groundwater and surface waters. It is worthy of note that naturally nitrogen is the most abundant gas in the atmosphere.

Nitrogen represents a critical nutrient upon which plant, microbial, and animal life depend, as it actively cycles through the atmosphere, the continental landmass and the world's oceans. The nitrogen cycle, in which the atmospheric nitrogen is changed into different organic compounds, is one the essential natural processes to sustain living organisms on earth. During the nitrogen cycle, bacteria in the soil process atmospheric nitrogen into ammonia, which plants need for growth. Also, other bacteria convert the ammonia into amino acids and proteins. In turn, animals eat the plants and consume the protein, and the nitrogen compounds are returned to the soil through animal waste or excreta. The bacteria in the soil convert the waste nitrogen back to nitrogen gas, which returns to the atmosphere.

Nitrate, which is the oxidized form of dissolved nitrogen, and the primary source of nitrogen for plants. Nitrates occurring naturally in the soil dissipate when humans excessively farm a particular land or soil. And in the bid to replenish the lost nitrate in the soil, humans tend to use nitrogenous fertilizers. Thus, the increase in nitrates from the widespread application of 
fertilizers, animal husbandry and point source sewage inputs with resultant changes to the nitrogen cycle have far-reaching effects on quality of water and public health, protein supply for humans, and even the planetary heat balance through the emission on nitrogen-based greenhouse gases. Nitrates can enter the food chain through groundwater and surface water supply, thereby exposing humans to diseases, as well as nitrate poisoning. Increased nitrate levels in people can affect the respiratory and reproductive systems, kidney, spleen and thyroid in children and adults. And nitrate poisoning is particularly dangerous to infants and fetuses, as it can lead to congenital disabilities and miscarriages in pregnant women. Nitrate poisoning has been linked to stomach and esophageal cancers in adults as well (Water Education Foundation, 2021).

\section{Ecosystems and Food Quality}

One of the significant routes of exposure for many pathogens and toxic chemicals globally is food. Food contamination is a severe threat to life. The proliferation of agribusiness and globalization and the consequent environmental pollution have exacerbated the problem in the planet today. Humans in the bid to increase food production have degraded the majority of the ecosystem services, which has come to hurt man. According to the US Centre for disease control and prevention, more than 11,000 foodborne infections occurred in 2013 (Salter, 2014), with agents like chemicals, metals and others causing food contamination (Callejon et al., 2015).

Food production has been identified as a significant force behind every direct driver of ecosystem degradation by the millennium ecosystem assessment in 2005. Man's natural habitat has been continually converted to croplands. It is estimated that about $43 \%$ of tropical and subtropical forests and $45 \%$ of temperate forests have been converted to farmland by humans. Due to overexploitation, about $70 \%$ of the global freshwater is used up by humans for agriculture, reducing its availability for other uses. In several countries around the world, agricultural intensification has resulted in farmers over-ploughing, over-fertilization, overirrigation, and over-application of fertilizers (nitrogen) and pesticides (DDT) (Ranganathan \& Hanson, 2018).

Pesticides such as DDT (dichloro-diphenyl-trichloroethane, a type of organochlorine) pose a danger to ecosystem food chains and the health of associated wildlife and human populations. They can be found in food even after washing and can travel several miles on wind, water and dust, thereby causing health symptoms such as nausea, diarrhoea, irritation of the eyes, nose or throat in low to moderate exposure; and humans can also suffer tremors, convulsions, and chromosomal damage in higher doses. The ingestion of foods contaminated with pesticides and heavy metals could result in arrays of gastrointestinal problems in the human population (Song et al., 2017). For example, in Nigeria (Zamfara) it was reported that about 400 to 500 children died of acute lead poisoning as a result of ingestion of food contaminated with lead-contained soil and dust (Tirima, Bartrem, von Lindern, et al., 2018).

Human food can also be contaminated by mixing chemicals in the animal feed or antibiotics injections administered to poultry animals. These chemicals in residual proportions in poultry meat and eggs can trigger series of biochemical reactions in the human body that could have a genotoxic, immunotoxic, carcinogenic, teratogenic endocrine-disrupting effects (Martin \& Beutin, 2011; Di Stefano \& Avellone, 2014). Also, DDT's has long-term devastating effects 
on aquatic life due to its low solubility and increased bioaccumulation rate in water, leading to decreased aquatic population and fish mortality.

\section{Ecosystems and Soil Quality}

Soil is a complex ecosystem in nature. It plays an essential role in supporting every life on earth, as it contains densely packed and diverse species of organisms that interact and contribute to the global cycle. The soil quality affects both human and animal health directly or indirectly. In the soil ecosystem, soil organisms usually perform essential functions that directly interact with the biological, atmospheric and hydrological systems. Moreover, some of these functions include nutrient cycling, regulation of the soil organic matter, soil carbon sequestration and greenhouse gas emissions, modification of the soil physical structure and water regimes and enhancement of plant health. These functions and interactions constitute an essential resource for the sustainable management of agricultural systems. The interactions between soil organisms and plants and animals in the ecosystem form a complex web of ecological activity called the soil food web (FAO, 2015).

The soil biological, chemical and mineral compositions can directly benefit or be detrimental to human health if ingested, inhaled or absorbed via the skin. Globally, many factors tend to degrade or reduce the soil's quality, including desertification, erosion, loss of organic matter, compaction and urban sprawl, the increased use of agricultural chemicals, and unsound animal and human waste management practices. Desertification is an example of extreme land degradation, which could arise from natural or human-made cause. Droughts and fires can be considered natural causes for desertification, while increasing human population and urban sprawl, livestock farming, fuelwood harvests, and deforestation are more important drivers of desertification caused by man. Globally, the grassland ecosystems in all regions of the world are subject to overexploitation, resulting in unfavourable weather patterns, which also tend to promote desertification. Desertification and other factors that lead to soil degradation eventually destroy the ecosystem structure, function, and health, resulting in a myriad of serious health and social problems, such as malnutrition, starvation, refugee and migration issues, and associated increases communicable disease, and death, for dependent human societies.

\section{Biodiversity and Human Health}

Biodiversity is used to describe divers' variety of life on earth. Specifically, it connotes all species in one region or ecosystem. Biodiversity supports human health through the supply of essential goods and services, supported by functional ecosystems. In addition, biodiversity is fundamental to key development sectors that regulate health outcomes directly or indirectly, such as forestry, agriculture, fisheries and tourism, on which an estimated 7.8 billion people relied upon for livelihoods.

Environmental degradation and biodiversity loss could portend a catastrophe to human health, particularly on health outcomes of the most significant vulnerable populations, particularly those most reliant on natural resources and not covered under the health insurance scheme. Significant vulnerable groups include women, children, indigenous populations, and those who depend highly on biodiversity and ecosystem services to survive, such as subsistence farmers. Human activities such as agricultural intensification and human- 
induced landscape changes, interacting in a co-evolutionary process, have resulted in the emergence of most infectious diseases among humans, animals, and plants.

Fragmentation of natural landscape may not just threaten biodiversity directly but also provides the potential for "edge effects" which has had reverberations As genetic and species diversity vanishes and human activities degrade ecosystems, the overall system's complexity becomes compromised. This makes the whole system more vulnerable and potentially creating new opportunities for disease emergence and poor health in humans (Smith, Acevedo-Whitehouse \& Pederson, 2009). It is worth noting that the loss of genetic diversity could, directly and indirectly, result in poor human health outcomes in several ways. For instance, biodiversity loss tends to expose plants and crops and make them more vulnerable to disease, thereby increasing the need for chemical fertilizers and pesticides by farmers, which can also contribute to numerous public health threats, including antibiotic resistance non-communicable diseases.

Furthermore, the loss of species diversity at the continental scales could change the ecosystem processes and disturbance regimes, and trigger chain of events leading to extinction, with consequences for human health (Rodolfo, et al., 2014). Also, changes in species diversity alter the ecosystem function and bring about a direct reduction in access to the provision of ecosystem services. It can also alter the availability of several species that control ecosystem processes necessary to provide those services.

\section{Measures to Control Anthropogenically Induced Ecosystem Dysfunction}

Measures to control man-made ecosystem dysfunction require coordinated efforts of the citizens and the government:

\section{Individual Level}

1. Behavioural change: Individual must change their behaviour towards the environment. For instance, individuals who make a living through fossil fuel industry can find other jobs that won't harm the environment so much.

2. Stop bush, to prevent the destruction of not only the vegetation but soil structure and composition.

3. Practice afforestation: Planting and growing trees helps to restore the ecosystem of an area, and also create a new ecosystem. It also prevents soil erosion, purifies the air, improves watersheds and stabilizes the climate.

4. Stop open dumping, to reduce the damages to the plants and wildlife habitats, and prevent the contamination of groundwater, streams, rivers and lakes.

5. Recycle and reuse to conserve resources and prevent the emissions of air pollutants.

6. Every individual ought to support climate legislation.

7. Individuals should be involved in politics. Speak up and make your voice heard. 
8. Write and discuss with community representatives at the lower or higher chambers about the policies the individuals or community would like to see, and share opinion and concerns regarding the growing climate crisis.

9. Have fewer children to avoid overpopulation.

10. Travel less with vehicle powered by gasoline or diesel to reduce greenhouse gas emissions. Research has shown that walking or biking can substitute for about 41 percent of short car trips, thus saving nearly 5 percent of carbon dioxide emissions from car travel (Andre \& Christian, 2019).

11. Adopt a plant-based diet: The eating of mostly plant-based foods and global reduction of the consumption of animal products, especially ruminant livestock, have the potential of improving human health and significantly lowering the greenhouse gas (GHG) emissions (William, Christopher, Thomas, Phoebe \& William, 2020).

\section{Governmental Level}

1. Increasing public awareness of the value of preserving and maintaining the human environment, and understanding the value of biodiversity through education.

2. Creation of National Parks to protect species biodiversity.

3. Establishment of policy on selective logging and replanting of trees to ensure that the rainforest canopy is preserved.

4. Policies and strategies should be focused on reducing greenhouse gas emissions.

5. Support for the International Commission for the Conservation of fishes and marine environment, and to ensure sustainable fishing on the high seas.

6. Banning the use of chemical pesticides such as dichlorodiphenyltrichloroethane (DDT) known for their ability to cause negative health effects in humans and wildlife and to degrade the natural environment.

7. Enactment of laws abolishing fossil fuel subsidies and taxing air pollution so that

8. green energy suppliers can compete fairly.

9. Investing and adopting alternative sources of energy, such as nuclear, solar, and wind.

10. Engaging in broad multilateral cooperation in mitigating climate change.

11. Adopting and implementing international agreements/treaties such as the Paris Agreement on reduction of greenhouse emissions.

12. Undertake international and regional negotiations on climate change.

13. Fund studies and support the development of appropriate technologies for climate change mitigation and adaptation. 


\section{CONCLUSION}

Anthropogenically induced pressures on ecosystems will have unpredictable and possibly considerable future effects on human health if not mitigated via concerted efforts. Interventions geared towards conserving the natural resources are more likely to succeed if individuals in the communities are well informed and given ownership of them, share the benefits, and are involved in decisions.

\section{REFERENCES}

Andre Neves \& Christian Brand (2019). Assessing the potential for carbon emissions savings from replacing short car trips with walking and cycling using a mixed GPS-travel diary approach, Transportation Research Part A: Policy and Practice, Volume 123, 2019, Pages 130-146, ISSN 0965-8564, https://doi.org/10.1016/j.tra.2018.08.022.

Callejón, R., Rodríguez-Naranjo, M., Ubeda, C., Hornedo-Ortega, R., Garcia-Parrilla, M., \& Troncoso, A. (2015). Reported foodborne outbreaks due to fresh produce in the United States and European Union: trends and causes. Foodborne Pathog. Dis. 12, 32-38. doi: 10.1089/fpd.2014.1821

Di Stefano V \& Avellone G (2014). Food contaminants. J Food Studies. 2014;3:88-102. doi:10.5296/jfs.v3i1.6192

Dirzo, Rodolfo, et al. (2014). "Defaunation in the Anthropocene." Science 345.6195 (2014): 401-406.

Ecosystem Conservation in a Changing Climate. World Resource

Endocrine-disrupting chemicals: implications for human health, The Lancet Diabetes \& Endocrinology, Volume 8, Issue 8, Pages 703-718. https://doi.org/10.1016/S22138587(20)30129-7

Food and Agriculture Organization of the United Nations (2015). Soils and biodiversity: soils host a quarter of our planet's biodiversity pdf. Retrieved from www.fao.org/documents/card/en/c/43b565e7-57c2-43c6-b4f0-812091486ed3/

Institute. Retrieved from https://www.wri.org/our-work/project/world-resources_report/tomorrows-approach-food-production-and-ecosystem

Laurance WF, Camargo JL, Luizão RC, Laurance SG, Pimm SL, Bruna EM, et al., (2011). "The fate of Amazonian forest fragments: a 32-year investigation". Biological Conservation 144(1): 56-67.

Linda G Kahn, Claire Philippat, Shoji F Nakayama, Rémy Slama, \& Leonardo Trasande (2020).

Loh, Elizabeth H., et al. (2015). "Targeting transmission pathways for emerging zoonotic disease surveillance and control." Vector-Borne and Zoonotic Diseases 15.7 (2015): 432-437.

Machalaba, C., Romanelli, C., \& Stoett, P. (2017). "Global Environmental Change and Emerging Infectious Diseases: Macrolevel Drivers and Policy Responses", in "Examining the Role of Environmental Change on Emerging Infectious Diseases and Pandemics" (pp. 24-67). IGI Global.Chicago.

Martin, A \& Beutin, L. (2011). Characteristics of Shiga toxin-producing Escherichia coli from meat and milk products of different origins and association with food producing animals as main contamination sources. Int. J. Food Microbiol. 146, 99-104. doi: 10.1016/j.ijfoodmicro.2011.01.041 
MEA. Millennium Ecosystem Assessment: A Framework for Assessment. Washington, DC: Island Press, 2003.

MEA. Millennium Ecosystem Assessment: Ecosystems and Human Well-being: Synthesis. Washington, DC: Island Press, 2005

Ranganathan Janet \& Hanson Craig (2018). Tomorrow's Approach: Food Production and

Salter, S. (2014). The food-borne identity. Nat. Rev. Microbiol. 12, 533-533. doi: $10.1038 /$ nrmicro3313

Simba Tirima, Casey Bartrem, Ian von Lindern, Margrit von Braun, Douglas Lind, Shehu Mohamed Anka, \& Aishat Abdullahi (2018). Food contamination as a pathway for lead exposure in children during the 2010-2013 lead poisoning epidemic in Zamfara, Nigeria, Journal of Environmental Sciences, Volume 67, 2018, Pages 260-272, ISSN 1001-0742, https://doi.org/10.1016/j.jes.2017.09.007.

Smith KF, Acevedo-Whitehouse K, \& Pederson A. (2009). The role of infectious diseases in biological conservation. Animal Conservation, 12:1-12.

Song, Q., Zheng, Y. J., Xue, Y., Sheng, W. G., \& Zhao, M. R. (2017). An evolutionary deep neural network for predicting morbidity of gastrointestinal infections by food contamination. Neurocomputing 226, 16-22. doi: 10.1016/j.neucom.2016.11.018

TEEB, (2010). The Economics of Ecosystems and Biodiversity: Mainstreaming the Economics of Nature: A synthesis of the approach, conclusions and recommendations of TEEB. p. 36.

Tilak Prasad Gautam, \& Tej Narayan Mandal (2018). "Storage and Flux of Nutrients in Disturbed and Undisturbed Tropical Moist Forest of Eastern Nepal", International Journal of Forestry Research, vol. 2018, Article ID 8516321, 12 pages, 2018. https://doi.org/10.1155/2018/8516321

Toledo Karina (2018). Human activities have already damaged $75 \%$ of Earth's surface. Retrieved from https://agencia.fapesp.br/human-activities-have-already-damaged-75-ofearths-surface/27534/Water Education Foundation, 2021. Nitrate Contamination. Retrieved from https://www.watereducation.org/aquapedia/nitrate-contamination

WHO (2018). Ambient (outdoor) air pollution. From https://www.who.int/en/newsroom/factsheets/detail/ambient-(outdoor)-air-quality-and-health

William J Ripple, Christopher Wolf, Thomas M Newsome, Phoebe Barnard, \& William R Moomaw (2020). World Scientists' Warning of a Climate Emergency, BioScience, Volume 70, Issue 1, January 2020, Pages 8-12, https://doi.org/10.1093/biosci/biz088 